Pò̀te et essayiste, André Gervais est né à Montréal en 1947. Actuellement professeur de littérature à l'Université du Québec à Rimouski et directeur de la revue Urgences. Dernier livre paru: La nuit se lève, poèmes et proses (Saint-Lambert: Ed. du Noroît, 1990).

\title{
Des bruits des brèches
}

\author{
Que'est-ce que lire?
}

Sinon l'entreprise illusoire de colmater des brèches*

Peut-on, doit-on répondre à une question impossible si simple?

Et la réponse allée avec la question et séparée d'elle par un point d'interrogation, un passage à la ligne et une majuscule ne forme-t-elle pas une seule phrase dont l'une des brèches est précisément cette brisure?

Et qu'est-ce que colmater une brèche sinon la fermer pour rétablir la continuité du front:

soir dans illusoire

nuit dans continuité

lire dans rétablir

lu dans illusoire

et le front de Mallarmé dans la main de fatigue et d'avancees sinon l'end'huire de lut mais il n'y en a pas une que l'ente reprise du fragmillocutoire ne désigne pas 
Que'est-ce que le silence dans la lecture?

Le silence est le sable des bruits

Lecteur je t'invite en silence à faire en silence

la lecture de l'écriture de ma lecture

[avec quelques grincements de plume]

en silence de ce que j'écris.**

Peut-on, doit-on répondre aussi à cette question impossible?

Pourtant la réponse est là: le silence

de ce que j'écris, de ce que je lis dans ce que j'écris,

que j'ai écrit,

de ce que j'écris de ce que je lis dans ce que j'ecris,

que j'ai écrit, et ainsi

de suite, le silence

est le sable

du temps, le sable

de la postérité

grains de sable dans grincements de plume

lu dans plume

de l'encrenage 
Trois maisons se heurtaient et formaient une petite cour. Cette cour contenait cependant deux ateliers installés dans des remises, et un grand tas de petites caisses dressé dans un coin. Une nuit de tempête extrêmement violente le vent chassait brutalement les trombes d'eau dans la cour par-dessus la plus basse de maisons, un étudiant qui veillait encore dans une mansarde, penché sur ses livres, entendit distinctement un son plaintif venant de la cour. Il tressaillit et écouta, mais tout restait silencieux, indéfiniment silencieux. "C'est sans doute une erreur," se dit l'étudiant, et il se remit à lire. "Pas d'erreur," dirent les lettres au bout d'un instant en composant littéralement la phrase dans le livre. "Erreur,» répéta-t-il, et, les guidant de l'index, il vint en aide aux lignes qui commençaient à s'agiter.***

Dans ce si bref récit, entre les trombes d'eau et les lettres

l'étudiant commence où finit la tempête Qu'est-ce que lire? Sinon l'imuption de dire

que constitue la réponse celle du livre où ça ne se conforme pas mais coïncide adhère dans pas d'erreur tempe et texte dans tempête extrêmement violente reprise: doigté du piéton $y$ aller de ce pas de ne pas y aller $y$ aller de ne pas à ça

*J.F. (1979)

**F.P. (1967)

***F.K. (1916) 